\title{
Forecasting Financial System Stability Using Vector Error Correction Model Approach
}

\author{
Setiawan', Moch. Trianto Utomo², Alfira Mulya Astuti³, M. Sjahid Akbar ${ }^{4}$, Imam \\ Safawi Ahmad5
}

1,2,4,5 Department Of Statistics, Institut Teknologi Sepuluh Nopember, Indonesia

${ }^{3}$ Department of Mathematics Education, Universitas Islam Negeri Mataram, Indonesia

Email: setiawan@statistika.its.ac.id, antoksmada@gmail.com, alfiramulyaastuti@uinmataram.ac.id,_m_syahid_a@statistika.ac.id, safawi@statistika.ac.id

\begin{abstract}
Indonesia is one of the developing countries whose economic system is still very dependent on other developed countries. This reliance often becomes one of the causes of the occurrence of economic turmoil sectors that interfere with financial system stability in Indonesia. Therefore, to forecast financial system stability indicators, primarily macroeconomic variables, become essential to do to provide an accurate index value. This research aims to forecast indicators that affect Indonesia's financial stability using the Vector Error Correction Model (VECM) approach. The indicators used are Banking Stability Index, Jakarta Stock Exchange Composite Index, Inflation, and Exchange Rate. Forecasting using the VECM method produces two models i.e., deterministic model using the intercept and deterministic model without intercept. The best model is a deterministic model with intercept and without a trend. The result of forecasting for Bank Stability Index, inflation, and exchange rate can be used to forecast 12 periods ahead. The Banking Stability Index affects Exchange Rate, the Jakarta Stock Exchange Composite Index, and Inflation.
\end{abstract}

Keyword: Financial; Macroeconomic; Forecasting; VECM Approach

\section{INTRODUCTION}

The stability of the financial system is a condition in which the economic mechanisms in pricing, allocation, and risk management function and supports economic growth [1]. The instability of the financial system of a country has a different cause in each state, depending on the components that dominate in the preparation of the financial system. Indonesia as a developing country has the elements of an economic system dominated by the banking sector, it can be seen from the results of the study by Bank Indonesia stated that the banking sector holds $77 \%$ of the total assets of the components of the financial system in Indonesia [2].

Indonesia's financial stability is related to two interrelated sources, namely external and internal. Based on the results of the Financial Stability Review (FSR) No. 30 March 2018 conducted by Bank Indonesia said that external factors which will affect the stability of the financial system in Indonesia that US trade protectionism policy and internal factors are expected to shake the financial stability in Indonesia, namely the volatility of inflation and exchange rate rupiah to dollar [3].

Research of financial system stability has been conducted by several researchers, including Wijaya [4], Qoirul [5], Akinsola dan Ikhide [6], Nadri et al. [7], Elijah and Hamzah [8], and Mande et al [9]. Based on previous studies, there is no justification regarding indicators that affect financial stability in Indonesia. Therefore, this research will forecast 
indicators that affect Indonesia's financial stability using the Vector Error Correction Model (VECM) approach. The financial stability indicators used in this study are inflation, exchange rate, Bank Stability Index (BSI), and the Jakarta Stock Exchange Composite Index (JSECI). The application of these indicators is based on the results of the Financial Stability Study (KSK) No. 30, March 2018. This method's advantages can understand the existence of a good relationship between economic variables in the form of a structured long-term relationship model [10].

This study is based on research conducted by Jenkin [11] who uses the VECM approach because the data used is a time series with first-order or more and with cointegration conditions (long term). The best selection criteria for the model used are Root Mean Square Error (RMSE) and Symmetric Mean Absolute Percentage Error (sMAPE).

\section{METHODS}

\section{Vector Error Correction Model}

Vector error correction model (VECM) is an interpreted vector autoregressive model, where the assumptions that must be fulfilled, namely the time series data, must be stationary in order one or more, and there is cointegration between variables [12]. The following is the specification of the model used in this study:

$$
\Delta \mathbf{y}_{\mathbf{n}, \mathbf{t}}=\boldsymbol{\mu}+\sum_{i=l}^{v} \boldsymbol{\Gamma}_{\mathbf{i}} \Delta \mathbf{y}_{\mathbf{1}, \mathbf{t - \mathbf { i }}}+\sum_{j=l}^{v} \boldsymbol{\Gamma}_{\mathbf{j}} \Delta \mathbf{y}_{\mathbf{2}, \mathbf{t - \mathbf { j }}}+\sum_{k=1}^{v} \boldsymbol{\Gamma}_{\mathbf{k}} \Delta \mathbf{y}_{3, \mathbf{t}-\mathbf{k}}+\sum_{l=l}^{v} \boldsymbol{\Gamma}_{\mathbf{1}} \Delta \mathbf{y}_{\mathbf{4}, \mathbf{t - 1}}+\boldsymbol{\alpha}\left[\sum_{n=l}^{4} \boldsymbol{\beta}_{n} \mathbf{y}_{\mathbf{n}, \mathbf{t}-\mathbf{1}}\right]+\mathbf{u}_{\mathbf{t}}
$$

\section{Measure of Evaluation}

The measure of evaluation model to know the models created can be used in the prediction of how the period by using Root Mean Square Error (RMSE) dan Symmetric Mean Absolute Percentage Error (sMAPE) [13]. The following are the equations for the RMSE and sMAPE method:

$$
\begin{gathered}
R M S E=\sqrt{\frac{\sum_{t=1}^{n}\left(y_{t}-y_{t}\right)^{2}}{n}} \\
S M A P E=\frac{1}{n} \sum_{t=1}^{n} \frac{\left|y_{t}-y_{t}\right|}{\left(\left|y_{t}\right|+\left|y_{t}\right|\right) / 2}
\end{gathered}
$$

Where $y_{t}$ is actual data at $t=1,2, \ldots, 12$, and the forecast results at the same $t$. If the two indicators have smaller values, the results of the predictions produced will be better.

\section{Forecast Error Variance Decomposition}

Forecast Error Variance Decomposition (FEVD) is a tool used to describe the shock (shock) on a variable to components of other variables used in modeling VECM. The variance decomposition in shock $j$ caused variable $i$ with a lag of $n$ can be written in the equation: 


$$
\frac{\sum_{k=0}^{n} \phi_{i j}(k)^{2}}{\sum_{k=0}^{n} \sum_{j=1}^{h} \phi_{i j}(k)^{2}}
$$

Where $i$ and $j$ is the number of variables used in this research and is the effect of structural shock on lag-k.

\section{RESULT AND DISCUSSION}

\section{Characteristics of Indicators of Financial System Stability in Indonesia}

Characteristics of the indicators of financial system stability in Indonesia are shown by the time series plot. The financial system stability indicators are used BSI, inflation, JSECI, and exchange rates. In Figure 1, time series plots from BSI, inflation, JSECI, and exchange rates will be presented:
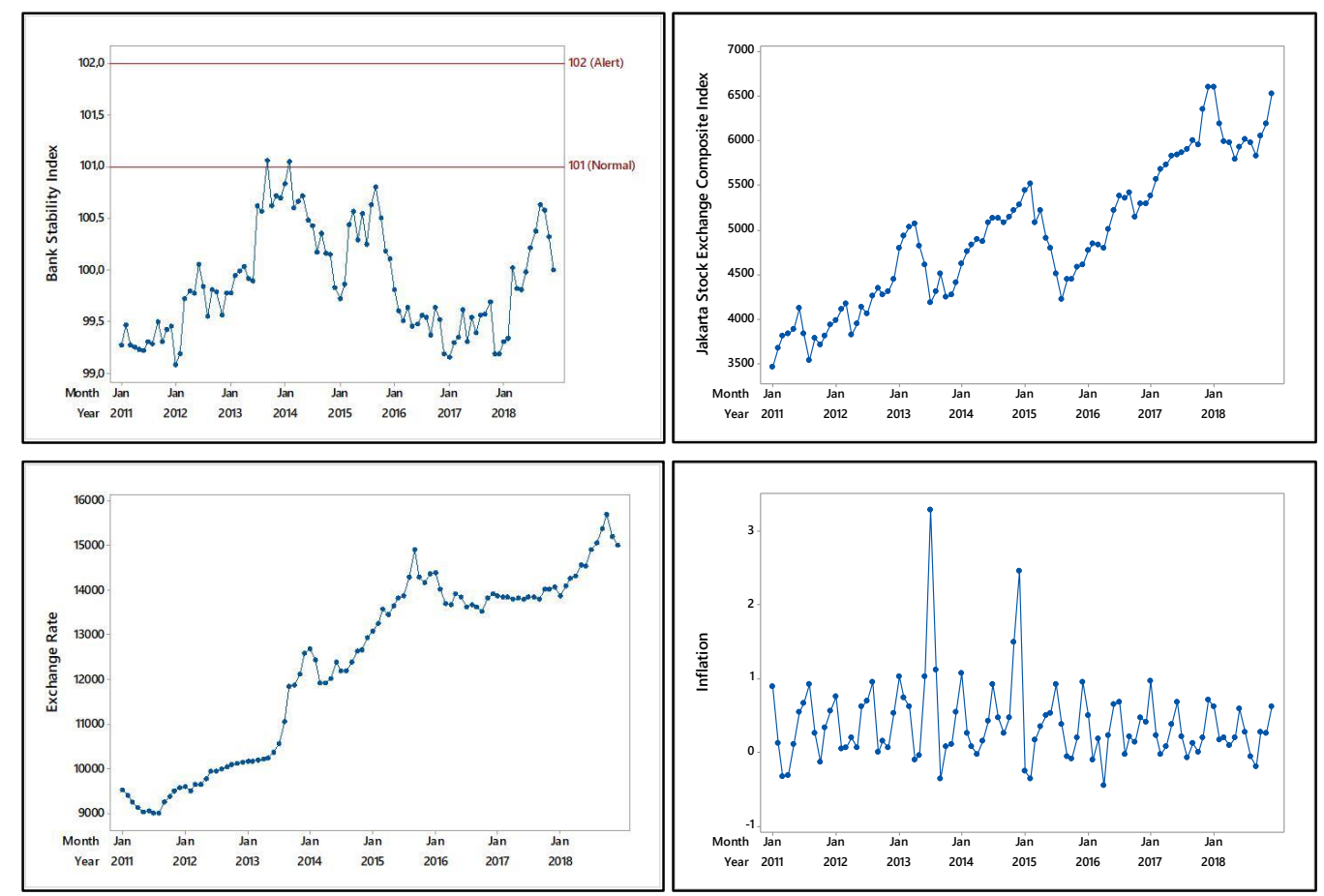

Figure 1. Time Series Plot of BSI, JSECI, Exchange Rates, and Inflations

Figure 1 shows that the development of BSIs in Indonesia from January 2011 to December 2018 is still in the normal position. The BSI value is below the 103 basis point (bps) figure. However, the condition of the BSI at the interval had been on the alert categories, namely September 2013 and early 2014. In Figure 1, it can also show that there was a decline in the largest JSECI value in 2015, from 2011 to 2017. The value of the JSECI opened at the level of Rp. 5,450,294 and closed at the level of Rp. 4,615,163 in December 2015. It can be seen in the period of January 2015. The highest increase in JSECI occurred in 2017. It can be seen in the period of January 2017. The value of the JSECI opened at the level of Rp. 5,386,691 and closed at the level of Rp. 6,605.63 in December 2017, wherein 2017 , the JSECI increased by $22.6 \%$ on an annual basis. 
Based on Figure 1, it can be seen that the value of the Rupiah exchange rate against the US Dollar experienced the weakest point in October 2018, which was Rp. 15,679. The condition of the Rupiah value was due to the trade war escalation between the United States and China. It caused a depreciation of the Rupiah to the highest point. In Figure 1, it can also show that inflation is highest at this period interval, namely in July 2013 and December 2014. The surge in inflation in the period of July 2013 was due to the increase in subsidized fuel prices in June 2013 which affected supply disruptions of some food commodities, resulting in the period of 2013 to be the year with the rate of inflation (year on year), the highest during the period January 2011 to December 2018 which amounted to $8.61 \%$.

\section{Modeling The Indicator of Financial System Stability with the VECM Approach}

The Vector Error Correction Model approach is used to forecast the indicators of financial system stability in Indonesia. The modeling of time series data using the VECM approach must meet two assumptions are stationary and cointegration. The following are the results of the stationarity test using the ADF test.

Table 1. Stationarity Test

\begin{tabular}{lcc}
\hline Variable & p-value & ADF Test \\
\hline BSI & 0.2794 & -2.01637 \\
\hline JSECI & 0.9148 & -0.33086 \\
\hline Inflation & 0.0000 & -8.21506 \\
\hline Exchange Rate & 0.8217 & -0.77115 \\
\hline
\end{tabular}

The stationarity test in Table 1 shows that the JSECI, BSI, and Exchange Rate data are not stationary both in the mean and in the variance. It can be seen from Table 1 , the p-value of JSECI, BSI, and Exchange Rate variables are more than the significant level (0.05). Hence, box-cox transformation and differencing will be carried out. After the data is stationary, cointegration testing will be carried out using the Johansen test. Table 2 is the results of the cointegration test.

Table 2. Cointegration Test

\begin{tabular}{cccccc}
\hline & \multicolumn{5}{c}{ Data Trend } \\
\cline { 2 - 6 } Rank & $\begin{array}{l}\text { None, No } \\
\text { Intercept, } \\
\text { No Trend }\end{array}$ & $\begin{array}{l}\text { None, } \\
\text { Intercept, } \\
\text { No Trend }\end{array}$ & $\begin{array}{l}\text { Linear, } \\
\text { Intercept, } \\
\text { No Trend }\end{array}$ & $\begin{array}{l}\text { Linear, } \\
\text { Intercept, } \\
\text { Trend }\end{array}$ & $\begin{array}{l}\text { Quadratic, } \\
\text { Intercept, } \\
\text { Trend }\end{array}$ \\
\cline { 2 - 6 } & \multicolumn{5}{c}{ Akaike Information Criterion } \\
\hline 0 & 21,5616 & 21,56180 & 21,6652 & 21,6652 & 21,76294 \\
\hline 1 & 21,4969 & 21,47900 & 21,5559 & 21,5460 & 21,61712 \\
\hline 2 & 21,5246 & $21,443^{*}$ & 21,4929 & 21,4754 & 21,52122 \\
\hline 3 & 21,6219 & 21,54704 & 21,5736 & 21,56524 & 21,59116 \\
\hline 4 & 21,8325 & 21,71441 & 21,7144 & 21,71323 & 21,71323 \\
\hline & & \multicolumn{5}{c}{ Data Trend } \\
\cline { 2 - 6 } Rank & None, No & None, & Linear, & Linear, & Quadratic, \\
& Intercept, & Intercept, & Intercept, & Intercept, & Intercept, \\
& No Trend & No Trend & No Trend & Trend & Trend \\
\cline { 2 - 6 } & \multicolumn{5}{c}{ Schwarz Information Criterion } \\
\hline 0 & $25,0225^{*}$ & $25,0225^{*}$ & 25,24960 & 25,24960 & 25,47092 \\
\hline 1 & 25,20494 & 25,21788 & 25,38750 & 25,40850 & 25,57230 \\
\hline 2 & 25,47978 & 25,45943 & 25,57165 & 25,61604 & 25,72360 \\
\hline 3 & 25,82430 & 25,84212 & 25,89957 & 25,98391 & 26,04074 \\
\hline 4 & 26,28206 & 26,28759 & 26,28759 & 26,41001 & 26,41001 \\
\hline
\end{tabular}


The Akaike Information Criterion (AIC) and Schwarz Information Criterion (SIC) criteria were used to test trend data from variable group data. Based on Table 2, the deterministic model is determined from the location of stars $\left(^{*}\right)$ for each indicator both SIC and AIC, where the best selection for both indicators is based on the smallest value of each indicator. From Table 2, it can be seen that the selected deterministic models are based on the values of AIC and SIC, namely models without trends and without intercepts and models without trends and with intercepts.

Two models were obtained from modeling with the VECM approach, namely the intercept and the model without intercept. Furthermore, the best model selection will be based on the value of RMSE and sMAPE. The best model will be used to forecast the sample data and predict the next 12 months of data after the testing data period. In Table 3, the values of RMSE and SMAPE are presented from the results of VECM modeling.

Table 3. Comparison Of RMSE and SMAPE Values from All Models

\begin{tabular}{llrr}
\hline \multicolumn{1}{c}{ Data } & \multicolumn{1}{c}{ Model } & \multicolumn{1}{c}{ RMSE } & \multicolumn{1}{c}{$\boldsymbol{s M A P E}$} \\
\hline BSI & Model Without Intercept & 0,10862 & 107,5686 \\
\hline \multirow{2}{*}{ Inflation } & Model With Intercept & 0,09728 & 103,4109 \\
\hline \multirow{2}{*}{ JSECI } & Model Without Intercept & 0,25487 & 20,2801 \\
\hline \multirow{2}{*}{ Exchange Rate } & Model With Intercept & 0,24986 & 21,2447 \\
\cline { 2 - 4 } & Model Without Intercept & 120,37740 & 94,7484 \\
\cline { 2 - 4 } & Model With Intercept & 120,34530 & 94,5959 \\
\cline { 2 - 4 } & Model Without Intercept & 9,52625 & 88,8382 \\
\hline
\end{tabular}

Table 3 shows that the best forecasting model chosen is the deterministic model with intercept and without a trend, for the five indicators of financial system stability in Indonesia. It can be seen from the data in the error rate on a smaller sample than a deterministic model with no intercept and no trend. The following is a model with an intercept with BSI as an endogenous variable:

$$
\begin{aligned}
\Delta B S I_{t}= & -1,33\left(B S I_{t-1}-0,00066 J S E C I_{t-1}-5,05 I N F_{t-1}+0,0124 E R_{t-1}+\right. \\
& 1,411)+0,245 \Delta B S I_{t-1}+0,181 \Delta B S I_{t-2}+0,129 \Delta B S I_{t-3}+ \\
& 0,216 \Delta B S I_{t-4}+0,12 \Delta B S I_{t-5}+0,27 \Delta B S I_{t-6}+0,23 \Delta B S I_{t-7}+ \\
& 0,00002 \Delta J S E C I_{t-1}-0,000188 \Delta J S E C I_{t-2}-0,000298 \Delta J S E C I_{t-3}- \\
& 0,000236 \Delta J S E C I_{t-4}-0,000078 \Delta J S E C I_{t-5}-0,000056 \Delta S E C I_{t-6}+ \\
& 0,000016 \Delta J S E C I_{t-7}-0,307 \Delta I N F_{t-1}-0,35 \Delta I N F_{t-2}-0,282 \Delta I N F_{t-3}- \\
& 0,191 \Delta I N F_{t-4}-0,219 \Delta I N F_{t-5}-0,157 \Delta I N F_{t-6}-0,11 \Delta I N F_{t-7}+ \\
& 0,0003 \Delta E R_{t-1}-0,00173 \Delta E R_{t-2}+0,000124 \Delta E R_{t-3}- \\
& 0,000826 \Delta E R_{t-4}+0,00092 \Delta E R_{t-5}+0,001238 \Delta E R_{t-6}+0,00006 \Delta E R_{t-7}
\end{aligned}
$$

\section{Forecasting the Indicators of Financial System Stability with the VECM Approach}

Forecasting on indicators of financial system stability performed on training data, the data testing, and forecast in January 2019 until December 2019 using the best models were selected based on the smallest value of RMSE and SMAPE. In Figure 2, time series plots from indicators of financial system stability will be presented: 


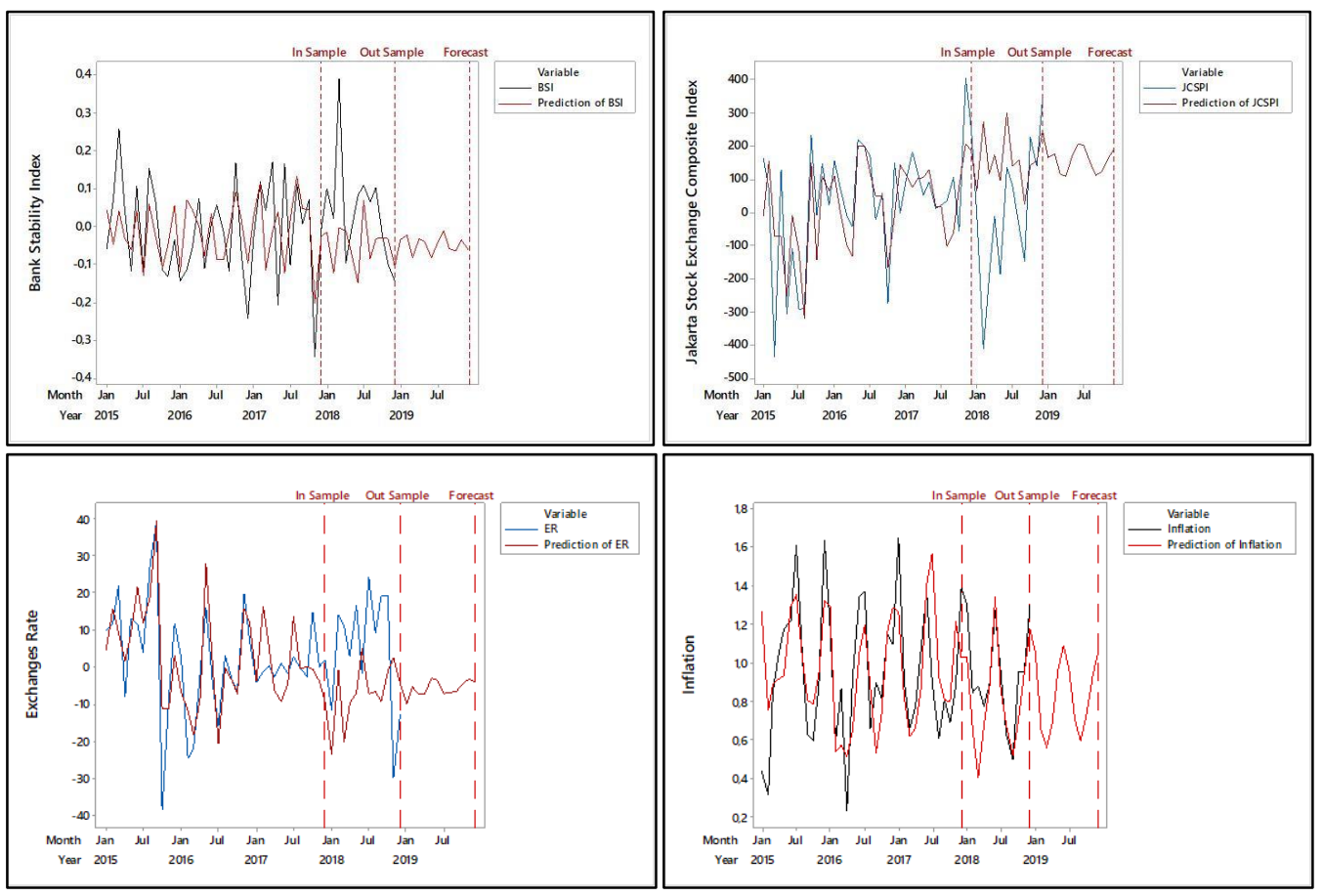

Figure 2. Time Series Plot Forecasting of BSI, JSECI, Exchange Rates, and Inflation

Figure 2 shows the results of predictions on testing data and the results of the forecast 12 months ahead for Inflation, BSI, JSECI, and Exchange Rates variables. In Figure 2 , it can be seen that the forecasting model using the best model for BSI, JSECI, Inflation Rate, and Exchange Rate each capable of use for 12 periods, 12 periods, a period, and 12 periods forward. It is shown in the forecast data pattern testing that follows the pattern of actual data of each variable.

\section{Forecast Error Variance Decomposition}

Variance Decomposition (VD) is used to see how much changes or the shock of an indicator contributes to other indicators or to itself. This study focused more on JSECI's shock contribution, inflation, and Rupiah Exchange Rate on the endogenous variable of the Banking Stability Index (BSI) in ten periods. Results of analysis of Variance Decomposition of each exogenous variable on endogenous variables (BSI) as presented in Table 4.

Table 4. Variance Decomposition: Banking Stability Index

\begin{tabular}{clrrrr}
\hline Period & S.E. & \multicolumn{1}{c}{ BSI } & JSECI & Inflation & \multicolumn{1}{c}{ E.R. } \\
\hline 1 & 0,131 & 100,000 & 0,000 & 0,000 & 0,000 \\
\hline 2 & 0,133 & 98,180 & 0,656 & 0,887 & 0,276 \\
\hline 3 & 0,139 & 89,066 & 7,025 & 2,560 & 1,349 \\
\hline 4 & 0,262 & 76,210 & 6,819 & 0,925 & 16,047 \\
\hline 5 & 0,280 & 67,588 & 6,494 & 7,988 & 17,931 \\
\hline 6 & 0,284 & 66,376 & 8,401 & 7,779 & 17,443 \\
\hline 7 & 0,302 & 60,792 & 7,924 & 10,467 & 20,816 \\
\hline 8 & 0,310 & 59,010 & 7,624 & 10,946 & 22,420 \\
\hline 9 & 0,320 & 58,325 & 7,195 & 10,939 & 23,540 \\
\hline 10 & 0,328 & 58,011 & 7,757 & 10,837 & 23,395 \\
\hline
\end{tabular}

Table 4 shows the summary of the Variance Decomposition analysis results for BSIs from shocks given by each variable, including itself. The VD analysis in Table 5 shows that in the short term, for the first month, the biggest shock is given by BSI itself, which is equal 
to $100 \%$, while for other variables, it still does not give shocks to the BSI. However, in the second period to the tenth shocks of JSECI, Exchange Rate, and inflation against BSIs tended to increase, and shocks caused by themselves decreased. In the long-term period, namely the 10th period, it can be seen that the shocks caused by the BSI itself, as well as the shocks caused by JSECI, Exchange Rate, and inflation are 74.07\%, 10.087\%, 8.71\%, respectively. $7.13 \%$. The shock is caused by the shock of each variable against endogenous as shown in Figure 3.

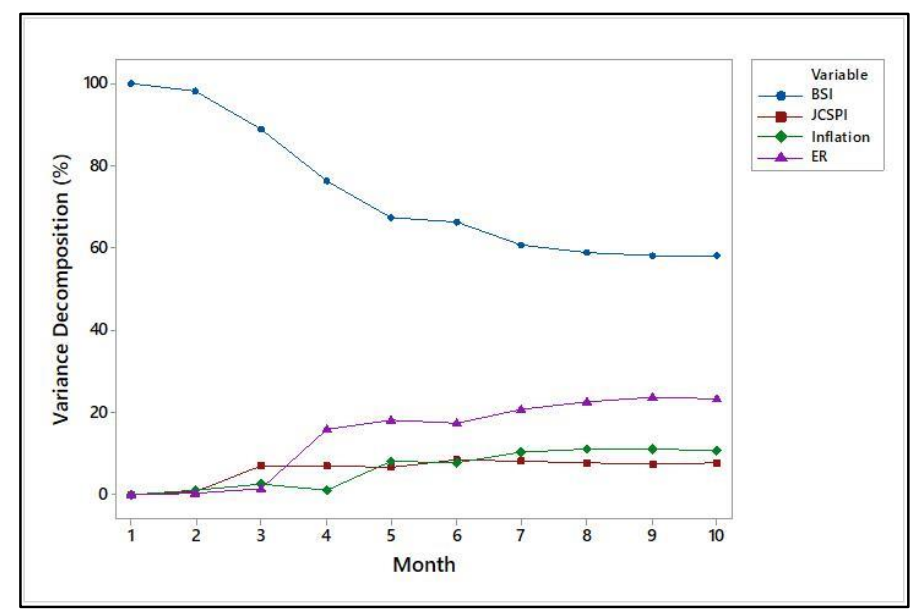

Figure 3. Variance Decomposition: Bank Stability Index

\section{CONCLUSIONS}

The best model is a deterministic model with intercept and without a trend. The Banking Stability Index (BSI) affects Exchange Rate, Jakarta Stock Exchange Composite Index, and inflation variables. The shocks or changes that occur at the BSI are responded fluctuatively by all of the exogenous variables. The result of forecasting for Bank Stability Index, inflation, and exchange rate can be used to forecast 12 periods ahead. The Jakarta Stock Exchange Composite Index (JSECI) based on the RMSE additive value can be used to predict for a period ahead. The results of Forecast Error Variance Decomposition show that in the long term, namely the 10th period, contributions itself getting weaker and the contribution of exogenous variables is increasing.

\section{REFERENCES}

[1] R. Siswosoemarto, D. V. Hasibuan dan D. D. Iskandar, Intelijen Ekonomi, Jakarta: PT Gramedia Pusaka Utama, 2012.

[2] Bank Indonesia, "Stabilitas Sistem Keuangan," 2012. [Online]. Available: http://www.bi.go.id.

[3] Bank Indonesia, "Bank Indonesia," March 2018.. [Online]. Available: http://www.bi.go.id.

[4] P. Wijaya, "Impact of Internal and External Shocks Monetary Policy on Financial System Stability in Indonesia," Faculty of Economics and Business, Universitas Airlangga, Surabaya, 2015.

[5] R. Qoirul, "Effect of Banking Industry Competition, Loan Intensity, Bank Size, and BI 
Rate on Financial System Stability in Indonesia," Universitas Airlangga, Surabaya, 2016.

[6] F. Akinsola and S. Ikhide, "Can Bank Capital Adequacy Changes Amplify The Business Cycle in South Africa?," Economic Research Southern Africa (ERSA), Southern Africa, 2017.

[7] K. Nadri, S. Ebrahimi and A. Fadaie, "Assessment of Financial Stability in the Banking," Journal of Money and Economy, vol. 13, no. 4, pp. 501-523, 2018.

[8] S. Elijah and N. Hamza, "The Relationship between Financial Sector Development and Economic Growth in Nigeria: Cointegration with Structural Break Approach," International Journal of Engineering and Advanced Technology (IJEAT), vol. 8, no. 5C, pp. 1081-1088, 2019.

[9] B. T. Mande, A. A. Salisu, A. N. Jimoh, F. Dosumu, and G. H. Adamu, "Financial Stability and Income Growth in Emerging Markets," Bulletin of Monetary Economics and Banking, vol. 23, no. 2, pp. 201 - 220, 2020.

[10] W. Enders, Applied Econometric Time Series, Fourth Edition, New York: John Wiley \& Sons, 2014.

[11] G. Jenkin, "Determinants of GDP: A VECM Forecasting and Granger Causality Analysis for Eight European Countries," Maynooth University, National University of Ireland, Ireland, 2014.

[12] D. Gujarati and D. C. Porter, Basic Econometrics Fifth Edition, New York: McGrawHiII/Irwin, 2008.

[13] W. W. S. Wei, Time Series Analysis Univariate and Multivariate Methods (Second Edition), USA: Pearson Education, 2006. 